\title{
Compliance-Time-Temperature Relationships from Inden- tation Measurements on a Pure-Gum Rubber Vulcanizate
}

\author{
Frank L. Roth, George W. Bullman, and Lawrence A. Wood
}

(March 29, 1965)

\begin{abstract}
Previous work on the calculation of shear compliance $J$ (limit of the ratio of strain to stress at zero deformation) from observations of the indentation of a flat natural rubber surface by a rigid sphere has been extended over greater ranges of time, temperature, and state of vulcanization. The extreme ranges of time were 5 sec to $23.5 \mathrm{hr}$ and of temperature -67 to $+100{ }^{\circ} \mathrm{C}$. The curves of $J T$ against $\log t_{-60}$ (where $t_{-60}$ is the equivalent time at $-60{ }^{\circ} \mathrm{C}$ and $T$ is in ${ }^{\circ} \mathrm{K}$ ) were sigmoid with a region of maximum slope and continuing through a region of minimum slope extending over about 7 decades. In contrast with the predictions of the Williams, Landel, and Ferry equation, the empirically determined shift of abscissa necessary to give a single $J T$ curve was found to be a linear function of $T^{-1}$ with a slope corresponding to an "apparent activation energy" of $36.9 \mathrm{kcal}\left({ }^{\circ} \mathrm{K}\right)^{-1}(\mathrm{~mole})^{-1}(154.5 \mathrm{~kJ}$ $\left.\left({ }^{\circ} \mathrm{K}\right)^{-1}(\mathrm{~mole})^{-1}\right)$.
\end{abstract}

\section{Introduction}

The calculation of shear compliance $J$ (limit of the ratio of strain to stress at zero deformation) from observations of the indentation of a flat rubber surface by a rigid sphere has been described in a previous publication [1]. ${ }^{1}$ Use was made of an instrument conforming to the requirements of ASTM Method D $1415-56$ T and equipped with a chamber for the maintenance of any constant temperature in the range from -100 to $+100{ }^{\circ} \mathrm{C}$. The present work was limited to studies with vulcanizates of a single recipe of natural rubber but covered more extensive ranges of time, temperature, and state of vulcanization than the previous work.

\section{Experimental Arrangements}

The shear compliance $J$ was obtained from the displacement of a ball indentor $2.38 \mathrm{~mm}$ in diameter under the standard load increase from 30 to $564 \mathrm{~g}$, as measured with a Wallace instrument $[2,3]$ having a scale graduated in International Rubber Hardness units. Details of the operation of the instrument and the calculation of the shear compliance $J$ from the scale readings are given in the previous paper [1].

In the present work use was made of only a single recipe (ASTM Formula 1A, Method D $15-59 \mathrm{~T}$, formerly called ACS-1 Recipe) as follows: Natural rubber (NBS 385a) 100; Zinc oxide (NBS 370a) 6; Sulfur (NBS 371b) 3.5; Stearic acid (NBS 372c) 0.5; and Mercaptobenzothiazole (NBS 383) 0.5 parts by weight. The rubber was cured $10,20,40$, or 80 min

\footnotetext{
1 Figures in brackets indicate the literature references at the end of this paper
}

at $140^{\circ}$. This recipe has been used more extensively than any other in the testing of natural rubber.

\section{Studies Over Extended Times}

Values of $J T$ (where $T$ is the temperature in ${ }^{\circ} \mathrm{K}$ ) were plotted against the logarithm of the time for each temperature. In the previous work the range of times at any temperature was about 2 decades. In the present work a few studies were undertaken to cover a range of time of about 4 decades $(5 \mathrm{sec}$ to $23.5 \mathrm{hr}$ ) at each of 3 temperatures. The three temperatures were chosen to give values of $J T$ corresponding respectively to the region of early rise, the region around the first point of inflection, and the region of reduced slope. An arbitrary quantity was subtracted from each observed value of the logarithm of the time in order to bring the three curves together in the single curve of figure 1, corresponding to a temperature of $-60{ }^{\circ} \mathrm{C}$. The arbitrary quantities are shown as $\log a_{-60}$ in figure 1 . For the purpose of orientation it is convenient to show a temperature scale (upper abscissa), which gives the temperature at which the 1-min compliance-temperature product has the value shown by the graph. The corresponding points are readily established at the temperatures of direct observation of the 1-min compliance. Discussion of the general relationship between equivalent time and temperature will be postponed until it can be covered more completely in the last section of this paper.

The figure shows two ranges of more than two decades each where the curve is determined by observations at two different temperatures and a shorter range where agreement is obtained among the results at all three temperatures. This is evi- 


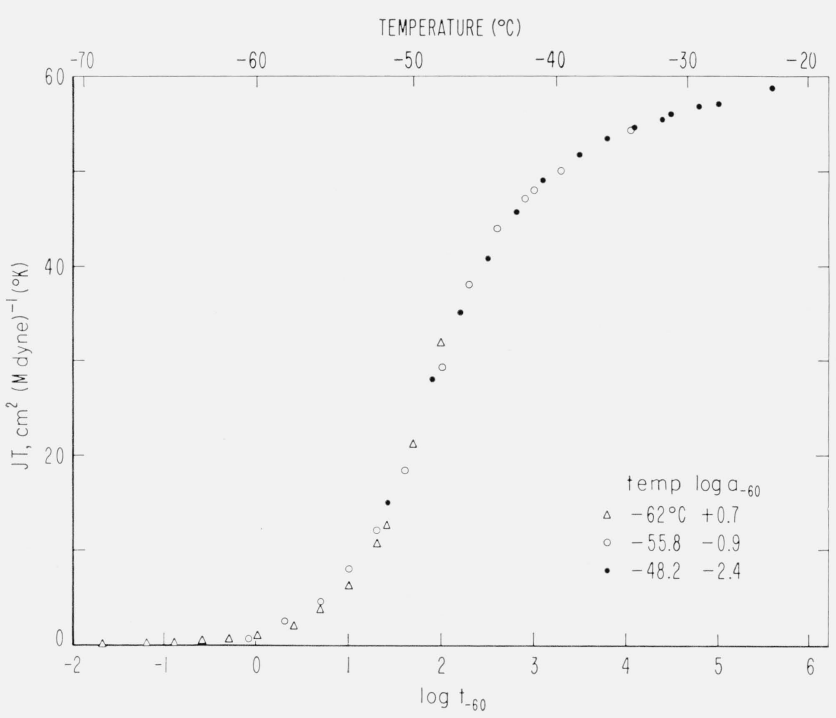

Figure 1. Compliance-temperature product plotted against logarithm of equivalent time (in minutes) at $-60{ }^{\circ} \mathrm{C}$.

Natural rubber vulcanizate ASTM-1A cured $80 \mathrm{~min}$ at $140{ }^{\circ} \mathrm{C}$. Scale at top shows temperature at which 1-min compliance-temperature product has value shown by graph. dence confirming the conclusion of many previous workers that for a given value of $J T$ the slope does not depend on the temperature. This is equivalent to establishing (over the range investigated) the essential validity of the principle of the equivalence of temperature and time in determining the compliance in this region.

In the data shown in figure 1 , because of the greater range of time, one can determine more exactly than in our previous work the empirical shifts in the time scale required to bring the JT curve for any temperature into coincidence with that corresponding to $-60^{\circ} \mathrm{C}$.

\section{Effects of Vulcanization on Compliance and Creep}

The effect of varying times of vulcanization is shown in figure 2. The curve marked "Unvulcanized" represents observations on a sample of NBS Standard Sample 385a (Natural Rubber), which was used as the basic rubber in the vulcanizates. This had been milled only enough to permit molding as a disk about $35 \mathrm{~mm}$ in diameter and $9 \mathrm{~mm}$ in thickness - the same size as the vulcanized samples.

In most instances the values are the means of 3-5 runs near each of the 7-28 temperatures selected for each specimen. Observations were normally made over the range from 5 to $600 \mathrm{sec}$ after the application of the load. With the unvulcanized sample, when $J T$ exceeded about $60 \mathrm{~cm}^{2}$ (M dyne $)^{-1}$ $\left({ }^{\circ} \mathrm{K}\right)$, there was a much greater scatter in the values than with the vulcanizates.

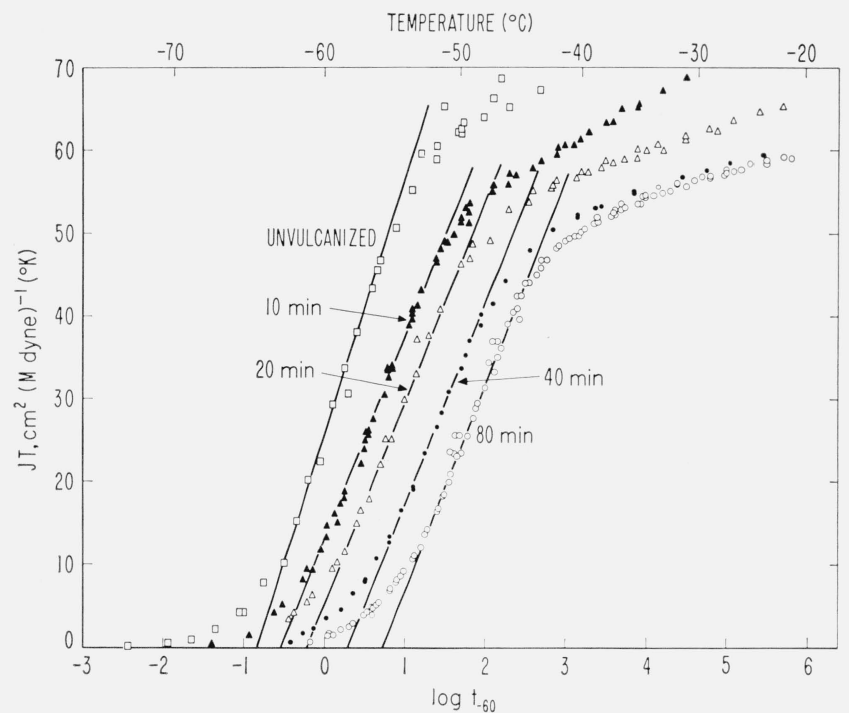

Figure 2. Compliance-temperature product plotted against logarithm of equivalent time (in minutes) at $-60^{\circ} \mathrm{C}$.

Unvulcanized natural rubber NBS-385a and vulcanizates ASTM-1A cured 10, 20,40 , or $80 \mathrm{~min}$ at $140^{\circ} \mathrm{C}$. Scale at top shows temperature at which 1 -min compliance-temperature product has value shown by graph. Straight lines represent tangents at point of maximum slope.

The values of $T_{a}$, defined as the approximate temperature at which the $1-\mathrm{min}$ value of $J T$ is 0.5 $\mathrm{cm}^{2}$ ( $M$ dyne $)^{-1}\left({ }^{\circ} \mathrm{K}\right)$ (a convenient small value, readily determined here), are given below, together with the corresponding values of time on the scale used in figure 2 .

\begin{tabular}{|c|c|c|}
\hline & $\log t_{-60}$ & $T_{a}$ \\
\hline $\begin{array}{l}\text { Unvulcanized rubber } \\
\text { Vulcanizate-10 min cure } \\
\text { Vulcanizate }-20 \text { min cure. } \\
\text { Vulcanizate-40 min cure. } \\
\text { Vulcanizate-80 min cure. }\end{array}$ & $\begin{array}{l}-1.95 \\
-1.4 \\
-1.1 \\
-0.51 \\
-0.22\end{array}$ & $\begin{array}{l}{ }^{\circ} C \\
-70 \\
-68 \\
-69 \\
-63 \\
-61\end{array}$ \\
\hline
\end{tabular}

Each value of $T_{a}$ is probably about $2 \mathrm{deg}$ above the corresponding glass transition temperature $T_{g}$ determined from volume-temperature relations [1].

As vulcanization proceeds, the glass transition temperature of natural rubber is raised at the rate of about $2.5{ }^{\circ} \mathrm{C}$ for each percent of combined sulfur (up to about 4\%), according to the mechanical and dielectric measurements of Payne [4] as well as the volume measurements of Martin and Mandelkern [5]. The changes in $T_{a}$ given in the preceding table (assumed to be the same as the changes in $T_{g}$ ) have been used to calculate the changes in combined sulfur with time of vulcanization. The results are in good agreement with those obtained for this recipe by Gee and Morrell [6], whose direct measurements of combined sulfur showed a linear 
increase at the rate of about 0.08 percent $/ \mathrm{min}$ up to a time of about $30 \mathrm{~min}$ followed by an asymptotic approach to the expected limiting value of 3.5 percent for this recipe at longer times of cure.

The values of the maximum slope of each curve (in fig. 2), together with the logarithm of the corresponding time, and the corresponding values of $J T$ are

\begin{tabular}{|c|c|c|c|}
\hline & $\begin{array}{c}\text { Slope } \\
\mathrm{cm}^{2}(M \text { dyne })^{-1} \\
\left({ }^{\circ} \mathrm{K}\right)(\text { decade })^{-1}\end{array}$ & $\begin{array}{l}\log \\
t_{-60}\end{array}$ & $\begin{array}{c}J T \\
\operatorname{cm}^{2}\left(\begin{array}{c}M \\
\text { dyne })^{-1} \\
\left({ }^{\circ} \mathrm{K}\right)\end{array}\right.\end{array}$ \\
\hline $\begin{array}{l}\text { Unvulcanized rub- } \\
\text { ber }\end{array}$ & 30.1 & 0.1 & 29. 2 \\
\hline $\begin{array}{l}\text { Vulcanizate } 10 \mathrm{~min} \\
\text { cure }\end{array}$ & 24.5 & .7 & 30. \\
\hline $\begin{array}{l}\text { Vulcanizate }-20 \mathrm{~min} \\
\text { cure }\end{array}$ & 24.1 & 1. 0 & 29. 9 \\
\hline $\begin{array}{l}\text { Vulcanizate }-40 \mathrm{~min} \\
\text { cure }\end{array}$ & 24. 2 & 1. 4 & 27. 0 \\
\hline $\begin{array}{l}\text { Vulcanizate }-80 \mathrm{~min} \\
\text { cure }\end{array}$ & 24.6 & 1. 8 & 27. 6 \\
\hline
\end{tabular}

The maximum slopes for the vulcanizates do not vary significantly with time of cure, but are appreciably less than that for the unvulcanized rubber. Perhaps this difference is related to the fact that the latter did not contain any vulcanizing ingredients. These, especially the zinc oxide, would be expected to produce a certain stiffening (reduction of compliance) in addition to that resulting from vulcanization.

Aside from this unimportant difference in slopes, the major effect of increased vulcanization at equivalent creep times less than those corresponding to the maximum slopes is a simple change in the time scale. This is apparent from the fact that the curves are approximately parallel to each other in this region. The amount by which the curve for each vulcanizate is shifted along the $\log t_{-60}$ scale from the position corresponding to the unvulcanized rubber is shown below:

\begin{tabular}{|c|c|c|}
\hline & $\begin{array}{l}\text { Shift measured at } \\
J T=0.5 \mathrm{~cm}^{2}(M \\
\text { dyne })^{-1}\left({ }^{\circ} \mathrm{K}\right)\end{array}$ & $\begin{array}{c}\text { Shift measured at } \\
J T=29 \mathrm{~cm}^{2}(M \\
\text { dyne })^{-1}\left({ }^{\circ} \mathrm{K}\right)\end{array}$ \\
\hline $\begin{array}{l}10-\min \text { cure } \ldots \\
20-\text { min cure } \ldots \\
40-\text { min cure } \ldots \\
80 \text {-min cure } \ldots\end{array}$ & $\begin{array}{l}0.55 \\
.85 \\
\text { 1. } 44 \\
1.73\end{array}$ & $\begin{array}{r}0.56 \\
.89 \\
\text { 1. } 49 \\
1.90\end{array}$ \\
\hline
\end{tabular}

The smaller value of $J T$ in this comparison is the one used in the determination of $T_{a}$ and the larger one was chosen to be close to the average value of $J T$ at the point of maximum slope.

Above the region of maximum slope, increasing the time of cure has additional effects besides the change in time scale, and the curves no longer remain parallel. At the higher values of $J T$ the shifts become greater than those just listed for each vulcanizate. In other words, the slope of the curve for a given value of $J T$, instead of remaining almostcon- stant with varying times of cure as in the lower region, decreases with increasing cure time. This behavior continues at temperatures and times higher than those considered in figure 2. This decrease of compliance and creep with increasing vulcanization is an expected characteristic of rubber undernormal conditions of vulcanization. This behavior is evident with the 10-, 20-, and 40-min cures in figure 2 .

When the time of cure is extended to $80 \mathrm{~min}$, however, the phenomenon of "reversion" begins to become apparent. As can be seen in figure 2, the difference in the shifts corresponding to the 40-min and the 80-min cures becomes less (rather than greater) at the higher temperatures and longer times of creep. This trend continues until the curves cross at a point beyond the range shown in figure 2 and it is clear that the longer vulcanization has led to an increased compliance and increased creep. The scission of chains is here considered to be predominant over cross-linking. The occurrence of reversion depends greatly on the nature of the accelerator and other vulcanizing ingredients. Gee and Morrell [6] and Stiehler and Roth [7] showed some years ago that for the recipe employed here, reversion becomes apparent for a cure time between 40 and $80 \mathrm{~min}$ at a temperature of $140^{\circ} \mathrm{C}$.

\section{Compliance at Higher Temperature}

Observations on the vulcanizate cured for $80 \mathrm{~min}$ were made over the temperature range from -60 to $+100^{\circ}$ in order to obtain the values of $J T$ given in figure 3. The results showed random deviations from the solid line but individual points always lay within the band defined by the dashed lines. The random deviations arose from uncertainties in both coordinates, of course, but here the effect of the uncertainty in $\log t_{-60}$ was found to be strongly predominant, since it involved judgment in the estimation of the amount of shift necessary for coincidence of two curves, whereas no such estimation was required for the other coordinate. As would be expected, the uncertainty in the amount of horizontal shift was greatest in the intermediate region where the slope was small and was changing very slowly. Here it was most difficult to prove the validity of the princple of the equivalence of temperature and time, and to obtain accurate values of the amount of shift involved. However, there was no evidence of failure of the principle in this region and the horizontal projection of the band of uncertainty became narrower again as the slope of the $J T$ curve increased once more at the highest values.

The $J T$ curve in figure 3 may be divided into three portions - a sigmoid region of rapid rise, a region of nearly constant slope, and a region of final upturn. The first region is dominated by effects associated with the glass transition (as discussed in the preceding section), the second is the region of normal rubber elasticity, and the third region includes deformation mechanisms not available at lower temperatures and shorter times. 


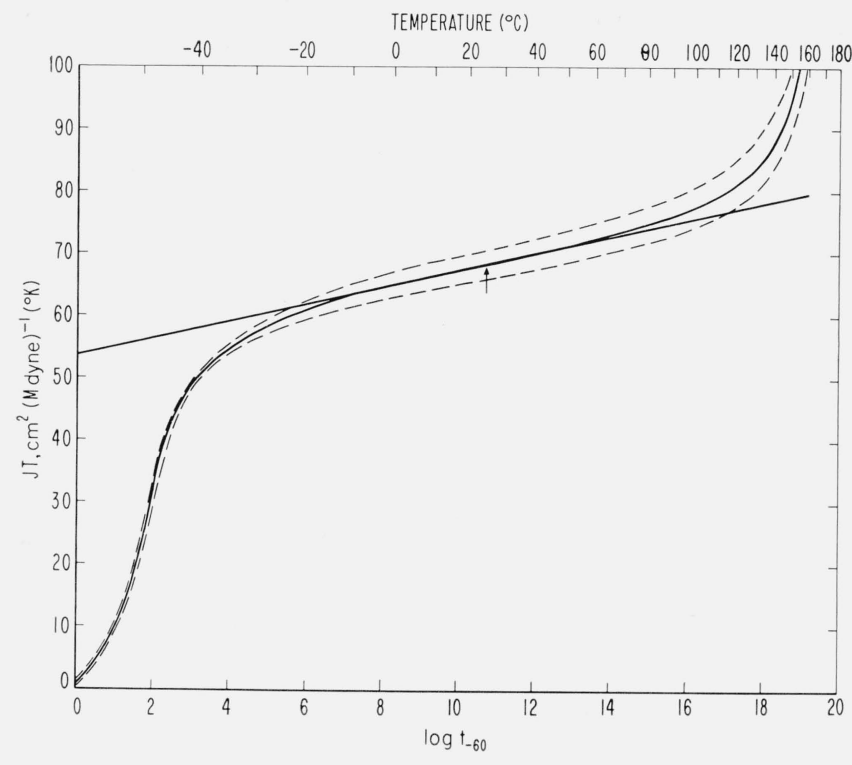

Figure 3. Compliance-temperature product plotted against logarithm of equivalent time (in minutes) at $-60{ }^{\circ} \mathrm{C}$.

Natural rubber vulcanizate ASTM- $1 \mathrm{~A}$ cured $80 \mathrm{~min}$ at $140{ }^{\circ} \mathrm{C}$. Scale at top shows temperature at which 1-min compliance-temperature product has (hows tenperature at which 1-1An conplince-tenperature product has Straight line represents tangent at second point of inflection. Arrow indicates 1-min compliance-temperature product at $25^{\circ} \mathrm{C}$.

In figure 3 the intermediate region extends from about 7 to 13.6 on the $\log t_{-60}$ scale, and the straight line shown would represent the $25^{\circ}$ data very well for times from $2 \times 10^{-4} \mathrm{~min}(12 \mathrm{msec})$ to about 8000 min, or alternatively the 1 -min creep data for temperatures from -10 to $+60{ }^{\circ} \mathrm{C}$. The ordinate value $J T]_{1,25}=68 \mathrm{~cm}^{2}$ ( $M$ dyne $)^{-1}\left({ }^{\circ} \mathrm{K}\right)$, corresponding to 1 -min creep at $25{ }^{\circ} \mathrm{C}$, designated by the vertical arrow at $\log t_{-60}=10.7$ in figure 3 , is near the center of the intermediate region for this vulcanizate.

In this region the viscoelastic behavior can be specified by reporting, for a given standard temperature and time, merely the values of $J T$ and its derivative with respect to $\log t$. In figure 3 the value of $J T]_{1,25}, 68 \mathrm{~cm}^{2}(M \text { dyne })^{-1}\left({ }^{\circ} \mathrm{K}\right)$, corresponds to a value of 'J $J_{1.25}$ of $0.228 \mathrm{~cm}^{2}(M \text { dyne })^{-1}$ and a Young's Modulus of $13.4 \mathrm{~kg} / \mathrm{cm}^{2}$. From the slope of the straight line in figure 3 the derivative here is found to be $1.36 \mathrm{~cm}^{2}(M \text { dyne })^{-1}\left({ }^{\circ} \mathrm{K}\right)$ decade $^{-1}$. From this one finds that $(1 / J T)_{1,25}(d J T / d \log t)_{1,25}=\left(1 / J_{1,25}\right.$ $(d J / d \log t)_{1,25}=2.0$ percent per decade.

When the logarithm of the ordinate is plotted on the vertical axis instead of the ordinate itself the slope in this region is reduced by a factor of $(2.303 \times$ $68)=157$. Almost all the previous workers have plotted the logarithm of the compliance (or modulus) as ordinate and thus have noted only a very small slope in this region. The name "rubbery plateau," often applied by those who use the logarithmic plot, does not seem to be appropriate for the region of minimum slope in figure 3 . Of course the logarithmic ordinate has real advantages for representing small values of $J T$. When the numerical value of $J T$ is less than 0.4342 , the slope becomes greater than that found in the type of plot we have used.

This intermediate region includes the conditions of normal use of most rubber products, and the behavior of a vulcanizate in this region is of much more practical significance than the behavior in the other regions. The values of compliance and its derivative in this region are in good accord with those reported by Gent [8] and by other workers mentioned in our previous paper [1].

The upturn of the curve at the longest times in figure 3 is undoubtedly the effect noted by many previous observers $[9,10]$ and sometimes denoted as "secondary creep." Gent, in a recent detailed study [11] of secondary creep in different vulcanizing systems, ascribes it to oxidative scission of the network structure. Gent's work showed the primary creep to be essentially completely recoverable, while the extent of recovery of the secondary creep depended greatly on the vulcanizing system.

In our work we obtained considerable creep recovery upon release of the load under all conditions, even following observations at the highest temperatures (up to $100{ }^{\circ} \mathrm{C}$ ) and longest times (up to $16 \mathrm{hr}$ ).

Observations reported here cover a range of values of equivalent time, almost 19 decades, which is greater than that given in any previous work with which we are familiar.

\section{Relation Between Time Factor and Temperature}

The curves presented in figures 1, 2, and 3 have been derived from observations at different temperatures by empirical shifts along the axis of $\log t$. The magnitudes of all the observed shifts are given in table 1.

A plot of these values as a function of $1 / T$, the reciprocal of the temperature in ${ }^{\circ} \mathrm{K}$, is represented remarkably well by a straight line over the whole range of observation, as can be noted in figure 4 . The equation of the line is

$$
\log a_{-60}=8.07 \times 10^{3} T^{-1}-37.85 .
$$

The intercept merely reflects the arbitrary choice of $-60{ }^{\circ} \mathrm{C}$ as the reference temperature. The slope corresponds to an "apparent activation energy" of $36.9 \mathrm{kcal}\left({ }^{\circ} \mathrm{K}\right)^{-1}(\text { mole })^{-1}\left(154.5 \mathrm{~kJ}\left({ }^{\circ} \mathrm{K}\right)^{-1}(\text { mole })^{-1}\right)$, obtained by multiplying the slope by the factor $2.303 R$, where $R$ is the gas constant $1.9872 \mathrm{cal}$ $\left({ }^{\circ} \mathrm{K}\right)^{-1}(\text { mole })^{-1}=8.3143 \quad \mathrm{~J}\left({ }^{\circ} \mathrm{K}\right)^{-1}(\text { mole })^{-1}$. The same line represents the shifts for the unvulcanized rubber as well as the vulcanizates cured 10, 20, 40, and $80 \mathrm{~min}$.

This very important and unexpected result indicates that the time scale of the molecular processes effective here changes with temperature in a manner not affected by vulcanization. The compliance itself and its derivatives are of course greatly altered by vulcanization, as shown in figure 2 . 
TaBle 1. Shifts relative to time at $-60{ }^{\circ} \mathrm{C}$

\begin{tabular}{|c|c|c|}
\hline \multirow{2}{*}{ Temp. } & Unvulcanized & \multirow{2}{*}{$\log a_{-60}$} \\
\hline & $T^{-1}\left({ }^{\circ} \mathrm{K}\right)^{-1} \times 10^{-3}$ & \\
\hline $\begin{array}{l}{ }^{\circ} \mathrm{C} \\
-66.7 \\
-59.3 \\
-55.3 \\
-50.9 \\
-25.0\end{array}$ & $\begin{array}{l}4.843 \\
\text { 4. } 675 \\
\text { 4. } 589 \\
4.498 \\
4.029\end{array}$ & $\begin{array}{c}+1.35 \\
-0.10 \\
-.90 \\
-1.70 \\
-5.3\end{array}$ \\
\hline $\begin{array}{r}-15.8 \\
-12.5 \\
-9.7 \\
0.0 \\
+9.0\end{array}$ & $\begin{array}{l}\text { 3. } 885 \\
\text { 3. } 836 \\
\text { 3. } 795 \\
\text { 3. } 660 \\
\text { 3. } 544\end{array}$ & $\begin{array}{l}-6.5 \\
-7.1 \\
-7.5 \\
-9.1 \\
-9.3\end{array}$ \\
\hline \multicolumn{3}{|c|}{ 10-minute cure } \\
\hline $\begin{array}{l}-57.7 \\
-56.2 \\
-55.5 \\
-55.4 \\
-54.7\end{array}$ & $\begin{array}{l}\text { 4. } 640 \\
\text { 4. } 608 \\
\text { 4. } 593 \\
\text { 4. } 591 \\
\text { 4. } 577\end{array}$ & $\begin{array}{r}-0.45 \\
-.55 \\
-.80 \\
-.85 \\
-1.10\end{array}$ \\
\hline $\begin{array}{l}-54.0 \\
-53.4 \\
-44.2 \\
-43.4 \\
-29.9\end{array}$ & $\begin{array}{l}\text { 4. } 562 \\
\text { 4. } 550 \\
\text { 4. } 367 \\
\text { 4. } 352 \\
\text { 4. } 110\end{array}$ & $\begin{array}{l}-1.10 \\
-1.20 \\
-2.70 \\
-2.90 \\
-4.20\end{array}$ \\
\hline \multicolumn{3}{|c|}{ 20-minute cure } \\
\hline $\begin{array}{l}-59.0 \\
-56.4 \\
-55.8 \\
-43.2 \\
-42.0\end{array}$ & $\begin{array}{l}\text { 4. } 669 \\
\text { 4. } 613 \\
\text { 4. } 600 \\
\text { 4. } 348 \\
\text { 4. } 325\end{array}$ & $\begin{array}{r}-0.15 \\
-.70 \\
-.85 \\
-2.90 \\
-3.15\end{array}$ \\
\hline $\begin{array}{l}-35.3 \\
-26.7\end{array}$ & $\begin{array}{l}\text { 4. } 203 \\
\text { 4. } 057\end{array}$ & $\begin{array}{l}-3.90 \\
-5.10\end{array}$ \\
\hline
\end{tabular}

\begin{tabular}{l|l|r}
\hline \multicolumn{3}{|c}{ 40-minute cure } \\
\hline-55.4 & 4.591 & -0.80 \\
-55.0 & 4.583 & -.95 \\
-54.0 & 4.562 & -1.10 \\
-46.5 & 4.411 & -2.55 \\
-44.1 & 4.365 & -2.85 \\
-32.7 & 4.158 & -4.45 \\
\hline
\end{tabular}

\begin{tabular}{|c|c|c|}
\hline \multicolumn{3}{|c|}{80 -minute cure } \\
\hline $\begin{array}{l}-62.0 \\
-60.0 \\
-55.8 \\
-55.7 \\
-53.7\end{array}$ & $\begin{array}{l}4.735 \\
4.690 \\
4.600 \\
4.598 \\
4.556\end{array}$ & $\begin{array}{r}+0.7 \\
-.00 \\
-.9 \\
-.65 \\
-1.12\end{array}$ \\
\hline $\begin{array}{l}-53.0 \\
-52.8 \\
-52.1 \\
-52.0 \\
-48.2\end{array}$ & $\begin{array}{l}4.543 \\
4.537 \\
4.523 \\
4.521 \\
4.444\end{array}$ & $\begin{array}{l}-1.18 \\
-1.28 \\
-1.20 \\
-1.53 \\
-2.4\end{array}$ \\
\hline $\begin{array}{l}-45.0 \\
-44.2 \\
-34.8 \\
-33.9 \\
-31.5\end{array}$ & $\begin{array}{l}4.382 \\
4.367 \\
4.195 \\
4.179 \\
4.137\end{array}$ & $\begin{array}{l}-2.65 \\
-2.75 \\
-4.00 \\
-4.20 \\
-4.50\end{array}$ \\
\hline $\begin{array}{r}-30.0 \\
-25.4 \\
-15.8 \\
-12.5 \\
-9.7\end{array}$ & $\begin{array}{l}4.112 \\
4.035 \\
3.885 \\
3.836 \\
3.795\end{array}$ & $\begin{array}{l}-4.70 \\
-5.3 \\
-6.3 \\
-7.1 \\
-7.5\end{array}$ \\
\hline 0.0 & 3. 660 & -8.7 \\
\hline $\begin{array}{r}+9.0 \\
+25.3 \\
+40.0 \\
+70.0\end{array}$ & $\begin{array}{l}\text { 3. } 544 \\
\text { 3. } 352 \\
\text { 3. } 193 \\
2.914\end{array}$ & $\begin{array}{r}-9.3 \\
-10.7 \\
-12.1 \\
-14.4\end{array}$ \\
\hline $\begin{array}{r}+85.0 \\
+100.0\end{array}$ & $\begin{array}{l}2.792 \\
2.680\end{array}$ & $\begin{array}{l}-15.4 \\
-16.5\end{array}$ \\
\hline
\end{tabular}

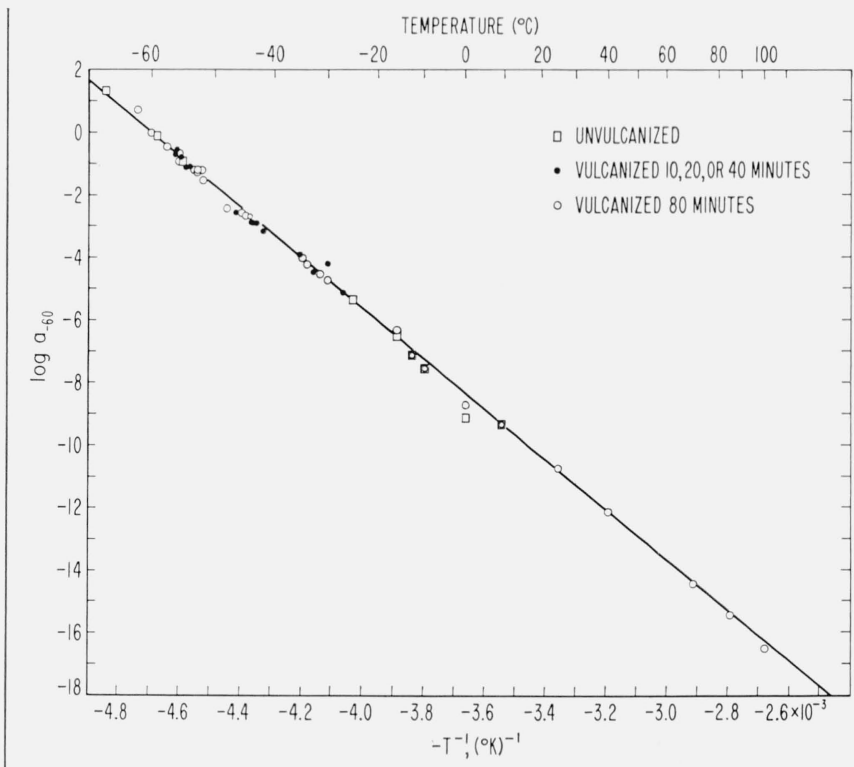

FIGURE 4. Shift in time scale required to produce coincidence of JT values with those observed at $-60^{\circ} \mathrm{C}$, plotted against reciprocal of temperature of observation in ${ }^{\circ} \mathrm{K}$.

Scale at top shows temperature in ${ }^{\circ} \mathrm{C}$. Straight line shown corresponds to "apparent activation energy" of $36.9 \mathrm{kcal}\left({ }^{\circ} \mathrm{K}\right)^{-1}(\text { mole })^{-1}\left(154.5 \mathrm{~kJ}\left({ }^{\circ} \mathrm{K}\right)^{-1}\right.$ $\left.(\text { mole })^{-1}\right)$. Data from table 1.

In our previous work [1] we reported similar results at temperatures above $-40{ }^{\circ} \mathrm{C}$ with an activation energy value of about $38 \mathrm{kcal} / \mathrm{mole}$, based on a much smaller number of observations. At the lowest temperatures $\left(-40\right.$ to $\left.-60^{\circ}\right)$ in the previous work, there appeared to be a deviation from the straight line in the direction of a considerable increase in the apparent activation energy. This was not found in the present investigation, which devoted particular attention to this region. We can offer no explanation for the discrepancy; we regard the present results as the more reliable.

The range of temperature over which the activation energy appears to remain constant is much greater than any range that has been reported in previous studies of the deformation of natural rubber vulcanizates. However, numerical values near $37 \mathrm{kcal} / \mathrm{mole}$ have been found by a number of workers in the region between 0 and $-50{ }^{\circ} \mathrm{C}$. In some instances larger values were found at lower temperatures (as in our previous work) and smaller values at higher temperatures; in others no change with temperature was observed over the range investigated.

Kobeko and coworkers [12], for example, report an activation energy of $39 \mathrm{kcal} /$ mole from measurements of primary creep recovery between -70 and $+12{ }^{\circ} \mathrm{C}$. Alexandrov and Lazurkin [13] plotted $\log \tau$ against $T^{-1}$ over the range -51 to $-23{ }^{\circ} \mathrm{C}$, where $\tau$ is the time corresponding to a maximum in the mechanical loss factor $\tan \delta$. From the slope of this graph one calculates a value of 37.6 [14] or $39 \mathrm{kcal} / \mathrm{mole}[15]$. 
The observations of dynamic modulus made by Zapas, Shufler, and DeWitt [16] on unvulcanized natural rubber have been presented by Ferry [17] in terms of apparent activation energy. From -50 to $0^{\circ}$ the values are close to those found in the present work; a slight decrease is noted at higher temperatures, and a very considerable increase is observed as the temperature is lowered to $-70^{\circ}$.

The data of Bueche [18] on the shift of creep compliances, for simple extension, of a pure-gum vulcanizate are well represented by a line corresponding to a constant activation energy of about $34 \mathrm{kcal} / \mathrm{mole}$ for temperatures from $-46^{\circ}$ to $+50{ }^{\circ} \mathrm{C}$. At lower temperatures higher values of activation energy are indicated.

Allen, Gee, and Read [19] find values decreasing from $37 \mathrm{kcal} / \mathrm{mole}$ at $-48{ }^{\circ} \mathrm{C}$ to $10 \mathrm{kcal} / \mathrm{mole}$ at $20{ }^{\circ} \mathrm{C}$ for the activation eneroy determined from the stress relaxation of natural rubber vulcanizates. Hopkins [20] has discussed the differences in apparent activation energies for the deformation of natural rubber as measured by different observers.

In contrast with the results reported here, the equation of Williams, Landel, and Ferry [21, 22] (WLF equation) predicts a monotonic decrease of apparent activation energy with increasing temperature, from values of 60 to $70 \mathrm{kcal} / \mathrm{mole}$ at the glass transition temperature to 16 to $17 \mathrm{kcal} / \mathrm{mole}$ at temperatures $100^{\circ}$ higher than $T_{g}$, when $-73^{\circ}<$ $T_{g}<-60{ }^{\circ} \mathrm{C}$. The data of Payne [4] on a pure-gum vulcanizate of natural rubber appear to conform to the WLF relation over a wide range of temperature. However, the apparent activation energies predicted by the equation and observed by Payne between -60 and $-35{ }^{\circ} \mathrm{C}$ differ from the value found here by less than the experimental error.

Above $-35{ }^{\circ} \mathrm{C}$, where the discrepancy becomes appreciable, Payne's plots of the logarithms of the reduced storage and loss moduli $G^{\prime}$ and $G^{\prime \prime}$ against $\log t$ have become nearly horizontal and the shifts are very difficult to determine. We consider the sensitivity of the logarithmic plots above $-35^{\circ} \mathrm{C}$ to be inadequate to evaluate the shift with sufficient accuracy to determine whether or not there is a change of apparent activation energy with temperature in this region. This is not the case in the present work where the slope of the JT plot in this region is about 157 times that of the logarithmic plot, as already mentioned. Consequently the slope is readily determined at all temperatures above $-35{ }^{\circ} \mathrm{C}$. Below $-60{ }^{\circ} \mathrm{C}$ the situation is reversed and the logarithmic plot is much more sensitive, since $J T$ and its derivative have both become very small.

We shall not attempt to discuss here the nature of the molecular processes $[8,11]$ involved in the deformations studied in the present work. It may be pointed out, however, that the activation energy for viscous flow in liquids is usually found to be in the range 5 to $15 \mathrm{kcal} / \mathrm{mole}$ [23] and the value for natural rubber has been given as 8 to $10 \mathrm{kcal} / \mathrm{mole}$ [24]. Treloar [15] has already called attention to the large difference between this value and that cal- culated from the observations of Alexandrov and Lazurkin. One concludes that irrecoverable flow involving the translation of whole molecules is not the fundamental process here.

Several previous workers $[22,25]$ have regarded a constant activation energy as normal at the higher temperatures and the WLF relation as representing merely deviations caused by the approach to the glass transition. The WLF equation has often been regarded as valid for temperatures from that of the glass transition $T_{g}$ to $T_{g}+100{ }^{\circ} \mathrm{C}$.

According to the present work in the case of natural rubber, either unvulcanized or in our puregum vulcanizate, this range of validity is found to be reduced to zero. We suggest the possibility that this behavior is associated with the fact that natural rubber approaches ideal rubber elasticity more closely than other systems that have been studied. It may be pointed out that in our previous work, extended regions of constant activation energy were found above $T_{g}+20{ }^{\circ} \mathrm{C}$ for pure-gum vulcarizates of butyl rubber and styrene-butadiene rubber, but not for chloroprene rubber or nitrile rubber. The latter two are polar polymers having higher glass transition temperatures, and their behavior deviates more from ideal rubber elasticity. Likewise we have not been able to find regions of constant activation energy for vulcanizates containing carbon black. These too show behavior deviating more from ideal rubber elasticity than the pure-gum vulcanizates. In this instance even the validity of the shifting operation is somewhat questionable.

Further work of this type should be conducted on vulcanizates of natural rubber with other curing systems and on other types of rubber. It would be especially interesting to know whether conditions could be found in which the apparent activation energies for butyl rubber (20 kcal/mole) and styrenebutadiene rubber (22 kcal/mole) would remain constant below the temperature limits, -40 and -25 ${ }^{\circ} \mathrm{C}$, respectively, found in our previous work.

\section{References}

[1] L. A. Wood and F. L. Roth, Creep of pure-gum rubber vulcanizates from indentation-time measurements Proc. Fourth Rubber Technology Conference, London, England, May 1962. Paper No. 28, p. 328, Institution of the Rubber Industry, London 1963; Rubber Chem. Technol. 36, 611 (1963).

[2] A. L. Soden, A practical manual of rubber hardness testing, India Rubber J. 120, 13 (1951).

[3] J. M. Buist, Physical testing of rubber. Chapter in book The Applied Science of Rubber, ed W. J. S. Naunton, p. 736 (Edward Arnold Ltd., London, 1961).

[4] A. R. Payne, Temperature-frequency relationship of dielectric and mechanical properties of polymers. Chapter in book Rheology of Elastomers, ed by $\mathrm{P}$. Mason and N. Wookey, p. 86 (Pergamon Press, London, 1958).

[5] G. M. Martin and L. Mandelkern, Glass formation in polymers: II The system rubber-sulfur, J. Res. NBS 62, 141 (1959) RP2944.

[6] G. Gee and S. H. Morrell, Quantitative characterization of cure. IV. Definition and measurement of rate of cure for pure-gum natural-rubber compounds, Trans. Inst. Rubber Industry 28, 102 (1952); Rubber Chem. and Technol. 25, 454 (1952). 
[7] R. D. Stiehler and F. L. Roth, Vulcanization characteristics of natural rubber, ASTM Special Technical Publication 136, p. 50 (1952); India Rubber World 127, 783 (1953); Rubber Chem. Technol. 26, 593 (1953).

[8] A. N. Gent, Relaxation processes in vulcanized rubber. I. Relation between stress relaxation, creep, recovery, and hysteresis, J. Appl. Polvmer Sci. 6, 433 (1962).

[9] S. D. Gehman, Creep, Recovery, and permanent set for GR-S and Hevea, J. Appl. Phys. 19, 456 (1948); Rubber Chem. Technol. 22, 105 (1949).

[10] G. M. Martin, F. L. Roth, and R. D. Stiehler, Behavior of pure-gum rubber vulcanizates in tension, Trans. Inst. Rubber Ind. 32, 189 (1956); Rubber Chem. Technol. 30, 876 (1957).

[11] A. N. Gent, Relaxation processes in vulcanized rubber II. Secondary relaxation due to network breakdown, J. Appl. Polymer Sci. 6, 442 (1962).

[12] P. Kobeko, E. Kuvshinskii, and G. Gurevich, Elasticity of amorphous bodies, Bull. Acad. Sci. USSR 3, 329 (1937) (in Russian) ; J. Tech. Phys. USSR 4, 622 (1937) (in English). See H. Leaderman, Textile Research 11, 171 (1941), and Reference [14], pages 32 and 80.

[13] A. P. Aleksandrov and Y. S. Lazurkin, A study of polvmers; I. Highly elastic deformation of polymers, J. Tech. Phys. USSR 9, 1249 (1939) (in Russian); Acta Physicochemica URSS 12, 647 (1940) (in English); Rubber Chem. Technol. 13, 886 (1940).

[14] H. Leaderman, Elastic and creep properties of filamentous materials and other high polvmers, p. 80 , Textile Foundation, Washington, D.C., 1943.
[15] L. R. G. Treloar, The physics of rubber elastic 2d Ed. (Oxford Univ. Press 1958).

[16] L. J. Zapas, S. L. Shufler, and T. W. DeWitt, Comparison of the dynamic properties of natural rubber and GR-S, J. Polvmer Sci. 18, 245 (1955).

[17] J. D. Ferry, Chapter in book ed by H. A. Stuart, Die Physik der Hochpolymeren, Vol. 4, p. 392 (in English) (Springer-Verlag, Berlin, 1956).

[18] F. Bueche, Mechanical properties of natural and synthetic rubbers, J. Polvmer Sci. 25, 305 (1957).

[19] G. Allen, G. Gee, and B. E. Read, Stress relaxation in elastomers by visco-elastic mechanisms; I. Natural rubber at high rates of strain and low temperatures, Trans. Faraday Soc. 55, 1651 (1959).

[20] I. L. Hopkins, The Ferry reduction and the activation energy for viscous flow, J. Appl. Phys. 24, 1300 (1953).

[21] M. L. Williams, R. F. Landel, and J. D. Ferry, The temperature dependence of relaxation mechanisms in amorphous polymers and other glass-forming liquids, J. Am. Chem. Soc. 78, 3701 (1955).

[22] J. D. Ferry, Viscoelastic properties of polymers, p. 228, (John Wiley \& Sons, Inc., New York, 1961).

[23] F. Bueche, Physical properties of polymers, p. 90, (Interscience Publishers, Inc., New York, 1962).

[24] Reference [15], p. 299.

[25] W. P. Slichter, Nuclear magnetic resonance studies of elastomers, Rubber Chem. Technol. 34, 1574 (1961).

(Paper 69A4-354) 